\title{
An Analysis of Design Problems in Combinatorial Procurement Auctions
}

This paper, selected for the category "Best papers from 1959 to 2008", was

first published in WIRTSCHAFTSINFORMATIK 47(2)2005:126-134.

Combinatorial auctions are promising auction formats for industrial and public procurement.

Potential advantages of using combinatorial auctions include lower overall spend, low

transaction costs for multi-item negotiations, fairness and market transparency for suppliers

as well as high allocative efficiency. A number of fundamental design considerations

are relevant to the application of combinatorial auctions in procurement. In addition, procurement specialists need to consider several domain-specific requirements, such as additional side constraints as well as alternative multidimensional bid types.

DOI 10.1007/s12599-008-0014-3

\section{The Authors \\ Prof. Dr. Martin Bichler \\ Dr. Alexander Pikovsky \\ Dr. Thomas Setzer \\ TU München \\ Department of Informatics (118), \\ Internet-based Informations Systems \\ Boltzmannstr. 3 \\ 85748 Garching/Munich \\ Germany \\ martin.bichler@in.tum.de}

This article is also available in German in print and via http://www. wirtschaftsinformatik.de: Bichler $M$, Pikovsky A, Setzer T (2008) Kombinatorische Auktionen in der betrieblichen Beschaffung - Eine Analyse grundlegender Entwurfsprobleme. WIRTSCHAFTSINFORMATIK. doi: 10.1007/11576-008-0119-9.

\section{Introduction}

Procurement negotiations on multiple items or services have typically been conducted as request for quotes (RFQ) or on the phone. Electronic auctions have found increasing adoption in procurement in the past couple of years. They allow for effective price negotiations on single items. Companies such as GlaxoSmithKline use electronic auctions for more than a third of their overall spend (Hannon 2004).
According to a study by the Center for Advanced Purchasing Studies companies use electronic auctions for $5 \%$ of their total spend. This proportion is expected to grow in the next few years (Beall et al. 2003).

An auction is defined as ,a market institution with an explicit set of rules determining resource allocation and prices on the basis of bids from the market participants" (McAfee and McMillan 1987). The competitive process serves to aggregate the scattered information about bidders' valuations and to dynamically set a price. The auction format determines the rules governing when and how a deal is closed. Klemperer (1999) provides a comprehensive introduction to classic auction theory.

Auctions exhibit high allocative efficiency compared to alternative types of negotiations in game-theoretical and experimental analyses (Kagel 1995). However, auctions have also been criticized in the context of procurement negotiations. Single-item reverse auctions are often considered insufficient for complex procurement negotiations where qualitative attributes of an item, multiple items, or also large quantities of an item are negotiated. Items can be goods or services in this case.

In the past couple of years, several new, "multidimensional“ auction mechanisms have been suggested in order to support also complex negotiations. Multidimensional auctions allow for complex bid types, a possibility for economic mechanism design that has become possible on nowadays computer networks. The term is based on dimensions such as quantity and quality of an item that are typically negotiated in procurement (Bichler et al. 2002). These types of auctions promise high allocative efficiency even in the presence of complex bidder preferences.

The best known multidimensional auction format is the combinatorial auction, which allows bids on bundles or packages of items (Cramton et al. 2005). Game theoretical and empirical analyses of combinatorial auctions are still in their infancy (Banks et al. 1989; Krishna and Rosenthal 1996; Isaac and James 2000; Kwasniak et al. 2003; Ewerhart and Moldovanu 2003). Nevertheless, these auctions have been successfully applied in a number of cases. In June 2002, Nigeria has conducted a combinatorial auction for spectrum licenses (Koboldt et al. 2003) and the U.S. Federal Communications Commission (FCC) plans their usage in the near future. There are also published cases of applications in industrial procurement and transportation. Examples are the procurement of transportation services at Sears Logistics (Ledyard et al. 2001), the procurement of goods and services at Mars, Incorporated (Hohner et al. 2003), applications at The Home Depot (Elmaghraby and Keskinocak 2002) and the procurement of school meals in Chile (Epstein et al. 2002).

Combinatorial auctions address fundamental questions regarding efficiency and 


\begin{tabular}{|c|c|c|c|c|c|}
\hline & & Bids & & & \\
\hline Line & Goods & B1 & B2 & B3 & B4 \\
\hline 1 & $\begin{array}{l}1000 \text { t Sugar } \\
\text { in Munich }\end{array}$ & 1 & 0 & 1 & 1 \\
\hline 2 & $\begin{array}{l}800 \text { t Sugar } \\
\text { in Bonn }\end{array}$ & 0 & 1 & 1 & 1 \\
\hline 3 & $\begin{array}{l}800 \text { t Sugar } \\
\text { in Berlin }\end{array}$ & 1 & 1 & 1 & 0 \\
\hline 4 & $\begin{array}{l}\text { Bid price (in } \\
\text { thousands) }\end{array}$ & $€ 150$ & $€ 125$ & $€ 300$ & $€ 125$ \\
\hline
\end{tabular}

prices in complex markets and are based on research results in Economics, Artificial Intelligence, Business and Information Systems Engineering, Information Systems, and Operations Research. Information systems play a crucial role as a means to facilitate these types of auctions effectively (Weinhardt et al. 2003). In this article we will discuss essential topics in the design of combinatorial auctions. We will address fundamental design problems and applications in the context of industrial procurement negotiations, which have a number of particularities.

In the next Section, we will provide an overview of various multidimensional auctions and important design goals. Section 3 discusses open and closed combinatorial auction formats. Section 4 gives an overview of applications in industrial procurement. Finally, Section 5 provides a summary of the main findings.

\section{Auction design with complex bid types}

In the simplest case, a multi-item auction is designed to sell multiple identical units of an item. Bids specify price and quantity, as it is common on financial markets with standardized assets. Combinatorial auctions have been discussed in the literature, as they allow negotiations on a set of heterogeneous items. Bidders can specify bundle bids, i. e., a price is defined for a specific subset of the items for auction (Cramton et al. 2005). The price is only valid for the entire set and the set is indivisible. For example, a bidder might want to sell 10 units of item $x$ and 20 units of item $y$ for a bundle price of $€ 100$, which could be less than the sum of the costs for $x$ and $y$ if sold individually. This bidding language is useful in markets with economies of scope, where suppliers have cost complementarities due to reduced production or transportation costs for a set of items.

Combinatorial auctions have been intensively discussed for the sale of spectrum licenses by the FCC (Milgrom 2000). The FCC devides licenses into different regions. Currently, the simultaneous multiple round auction (SMR) is used to allocate these licenses, i. e., multiple auctions are conducted in parallel. Bidders, usually large telecom companies, have strong preferences for licenses that are adjacent to each other. This can have advantages in advertising a service to the end customer, but also in the infrastructure that needs to be set up. In simultaneous auctions, bidders risk that they only win one item from a set of items that they are interested in, but that they end up paying too much for this item. This is also called the exposure problem. These types of preferences can easily be considered in combinatorial auctions. In the mid-1990s these auctions have, however, been considered impractical (McMillan 1994) for at least two reasons:

- the computational complexity of the winner determination problem,

- the strategic complexity for bidders.

The allocation problem in combinatorial procurement auctions is a weighted set packing problem, a well-known NP-complete problem (de Vries et al. 2003). We will discuss this central problem in more detail in the next subsection. Strategic complexity for bidders has turned out to be another difficult problem. Bidders need to know their valuations for $2^{m}-1$ possible bundles of $m$ items in the auction. Even if they know all valuations, they need to determine an optimal bidding strategy. Researchers have proposed different auction formats which exhibit various degrees of strategic complexity for bidders (see Section 3).

\subsection{The winner determination problem}

First, we will concentrate on the winner determination problem in combinatorial procurement auctions. It is an excellent example of the types of optimization problems that one encounters in various multidimensional auctions. The following example with 4 bids and 3 items illustrates a simple setting. The buying organization needs different quantities of sugar in different production sites. In this case, the buyer aggregates demand for multiple production sites, as suppliers might be able to provide better prices due to reduced production and transportation costs. Suppliers bid on subsets of the demand and each subset has a bundle price (see Tab. 1).

The optimization problem can be formulated as a binary program. There are $j \in L$ bids, and the set of items $M$ indexed with $k=1, \ldots, m$. Each supplier $i \in N$ submits a set $L^{i}$ of bids. Each bid $b_{i j}$ has a price $p_{i j}$ and the set of items in a bid is described by a binary vector $a_{i j}^{k}$. If bid $b_{i j}$ satisfies the entire demand of item $k$, then $a_{i j}^{k}=1$, otherwise 0 . The winner determination problem (WDP) can be formulated as follows:

$$
\begin{array}{cc}
\min & \sum_{i \in N} \sum_{j \in L^{i}} p_{i j} x_{i j} \\
\text { s.t. } & \sum_{i \in N} \sum_{j \in L^{i}} a_{i j}^{k} x_{i j} \geqslant 1 \\
& \multicolumn{2}{c}{\quad x_{i j} \in\{0,1\}} \\
\forall k \in M \quad \text { (a) } \\
\forall i \in N, \forall j \in L^{i} \quad \text { (b) }
\end{array}
$$

The decision variable $x_{i j}$ is 1 , if bid $b_{i j}$ is a winner in the auction, otherwise 0 . Constraint (a) ensures that the total supply of items satisfies the demand. In other words, lines 1 to 3 in Tab. 1 are transformed into side constraints of the binary program. Line 4 is transformed to the objective function. Note that the cost minimal solution can provide more items than the actual demand specified for the different sites.

This allocation problem is NP-complete, i. e., while the allocation problem in simple auctions is trivial, we do not know polynomial time algorithms for the winner determination problem in combinatorial auctions. Rothkopf and Pekec (1998) analyze different approaches to limit the bidding language in order to solve the allocation problem in polynomial time. Unfortunately, in every known case, the restriction required is so severe as to make the design impractical for any real-world 
auction. Independently, different algorithmic approaches for exact or heuristic solutions have been analyzed (de Vries and Vohra 2003). Existing methods from combinatorial optimization have been used, but also new algorithms have been developed (Sandholm 1999). The problem sizes in many real-world applications have shown to be tractable. Most instances of the winner determination problem with several dozens of items and several hundred bids can be solved in a few seconds. For example, the combinatorial auction for Sears Logistics comprised 850 items (Kwasniak et al. 2003). Some papers have suggested meta heuristics for very large auctions with many bidders and many items. Optimality of an allocation, however, is important for the allocative efficiency of an auction.

In addition to the basic formulation of the winner determination problem, procurement applications often require additional side constraints such as:

- Purchasing managers want to specify a lower bound on the number of winners in order not to become dependent on a single supplier. They also specify an upper bound to limit transaction costs due to too many suppliers.

- They also specify bounds on the quantity or volume purchased from a particular supplier or a group of suppliers (e. g., quotas for small- and mediumsized enterprises).

Side constraints of this sort can significantly impact the solution time for the winner determination problem (Davenport and Kalagnanam 2000).

\subsection{Other types of multidimensional auctions}

Apart from bundle bids, other types of complex bids have shown to be useful in procurement. Volume discount bids allow for bids specifying supply curves, i. e., unit prices for different quantities of an item sold (Davenport and Kalagnanam 2000). With this type of bids supplier can express economies of scale when bidding on very large quantities (e. g., $€ 500 /$ unit until 1000 units and $€ 450 /$ unit for more than 1000 units). Typically, buyers need to consider various business constraints when selecting such bids. For example, there might be limits on the spend per bidder or group of bidders, and upper and lower bounds on the number of winners. These side constraints turn the winner determination problem into a hard computational problem.

Multi-attribute auctions allow bids on price and qualitative attributes such as delivery time or warranty. In contrast to request for quotes or tenders as they are regularly used in procurement, the purchasing manager specifies a scoring function that is used to evaluate bids (Bichler 2001). This enables competitive bidding with heterogeneous, but substitutable offers. In addition to game theoretical models (Che 1993; Brandt 2003), several implementations have been proposed and tested experimentally in the past few years (Bichler et al. 1999; Bichler 2000; Bichler and Klimesch 2000; Strecker 2003). Multi-attribute auctions differ in the types of scoring rules or functions used, and in the type of feedback that is provided to bidders. These implementation specifics can have a significant impact on the auction results and are beyond what has been analyzed in game theoretical models. Depending on the type of bids submitted and on the type of (linear or non-linear) scoring function, the auctioneer faces different optimization problems. For example, Bichler and Kalagnanam (2005) describe allocation problems for configurable offers describing the price of an item as a function of attribute values. These types of bids allow for a compact representation of pricing policies (e. g., CPU $A$ has a markup of $€ 100$ for a laptop, while CPU $B$ has a markup of $€ 150$; the purchase of operating system $X$ and office package $Y$ implies a discount of $€ 60$; operating system $X$ and office package $Z$ are incompatible, etc.). These rules can be described in offers and automatically considered by the buyer in the bid evaluation or winner determination respectively. The scoring function and the bid type have implications on the computational complexity of the allocation problem, but also on the strategic complexity for bidders. As of now, there is little research on these questions.

\subsection{Desirable economic properties}

Efficiency, revenue properties, and optimal bidding strategies of different auction formats are at the core of traditional auction theory (Wolfstetter 1996). So far, there has been a limited amount of game theoretical work on combinatorial and other types of multidimensional auctions. On the one hand, combinatorial auctions are a relatively young field. On the other hand, they are much harder to analyze game theoretically than single-item auctions.

Before we will discuss specific combinatorial auctions, we will introduce a number of desirable economic properties. Auction design describes the rules of an auction. These rules incent bidders to reveal their private valuations or costs respectively, so that the auctioneer is able to determine the efficient allocation based on the bidders' true valuations.

Two types of goals are regularly discussed in the literature (Jackson 2000):

- Allocative Efficiency is achieved, if the auction leads to an allocation that maximizes the sum of all payoffs of the bidders and the auctioneer.

- Revenue maximization is achieved, if the auctioneer maximizes his revenue (or minimizes his cost in a procurement auction). This is often called „optimal“ auction design.

Incentive compatibility and strategy proofness are properties that should incent bidders to reveal their private valuations. An auction is incentive compatible, if truthful revelation is a Bayes Nash equilibrium, i. e., truth revelation is optimal, if also all other bidders reveal their true valuations. An auction is strategy proof, if truth revelation is even a dominant strategy for bidders, i. e., it is the bidder's best strategy independent of other bidders' strategies. In these cases, the strategic complexity of an auction is reduced to a minimum and speculation is not necessary.

Apart from properties such as allocative efficiency or revenue maximization, individual rationality and budget balance are additional desirable properties. An auction mechanism is individually rational, if all participants have a positive expected utility. Budget balance requires that the auctioneer must not make a loss. There are proofs showing that it its impossible to have bilateral trading mechanisms that are efficient, budget-balanced, incentive compatible, and individual rational subject to certain assumptions (Myerson and Satterthwaite 1983).

Game theoretical and experimental analyses of combinatorial and general multidimensional auctions are in their infancy. Due to the difficulties of analytical models in this field, many researchers have started with lab experiments on new auction designs and then derive useful theory from these observations, rather than starting with theory develop- 


\begin{tabular}{llll|}
\hline & \multicolumn{1}{l}{ Tab. 2 Vids (bundle prices) } & & \\
\cline { 2 - 4 } & $\{x\}$ & $\{y\}$ & $\{z\}$ \\
\hline Supplier 1 & 20 & 11 & 30 \\
\hline Supplier 2 & 14 & 14 & 26 \\
\hline
\end{tabular}

ment and then testing it in the lab. These types of experiments are sometimes called „wind-tunnel experiments“.

\section{Combinatorial auctions}

Apart from the type of bids allowed, a format describes the rules of the message exchange protocol. This protocol and the pricing rules determine the strategic complexity of auctions.

\subsection{Sealed-bid auctions}

One can distinguish between sealed-bid and open auctions. In sealed-bid auctions, bidders submit their bids to the auctioneer without additional information feedback until the auction closes. In open auctions, bidders can see information about what other bidders have bid. The first and the second-price sealed-bid auction (a. k. a. Vickrey auction) are well-known sealedbid formats.

\subsubsection{The first-price sealed-bid auction}

Some applications of combinatorial auctions are based on sealed-bid formats (Elmaghraby and Keskinocak 2002; Epstein et al. 2002; Rassenti et al. 1982). All bids need to be submitted until a particular end date, when the cost-minimizing combination of bids is selected. A number of properties of single-item sealed-bid auctions can also be observed in combinatorial auctions. First-price sealed-bid auctions are robust against collusion (Robinson 1985). However, the strategic complexity is quite high as compared to the Vickrey auction or generalizations of the English auction. For example, the bidder with the lowest cost for an item could speculate that others have higher cost and bid above his true cost. While he would increase revenue, it might also happen that he does not win. The strategic complexity arises in determining an optimal bid, given stochastic information about the cost distribution of competitors. In comparison, English auctions have a simple dominant strategy of bidding down to the true cost, and then win or drop out of the auction.

Vickrey-Clarke-Groves (VCG) mechanisms describe a class of strategy-proof economic mechanisms (Vickrey 1961; Groves 1973), where sealed bids are submitted to the auctioneer. The principle can be applied to combinatorial auctions and is also called Generalized Vickrey auction (GVA). GVAs have a number of favorable properties, but also a few problems that should be discussed in the following.

Similar to single-item Vickrey auctions, bidders submit their private costs to the auctioneer. In a GVA, this means, a bidder needs to submit bids on all possible bundles. Each winning bidder receives a Vickrey payment, which is the amount that he has contributed to lowering the total cost of the buyer. Let's assume two items $x$ and $y$ should be purchased. Supplier 1 bids $€ 20$ for $\{x\}$ (i. e., $\left.B_{1}(x)=€ 20\right), B_{1}(y)=€ 11$ and $B_{1}(x, y)=€ 30$. Supplier 2 bids $B_{2}(x)=€ 14$, $B_{2}(y)=€ 14$ and $B_{2}(x, y)=€ 26$ (Tab. 2). The total cost will be minimized at $€ 25$, while purchasing $\{x\}$ from supplier 2 and $\{y\}$ from supplier 1 . Supplier 1 demands $€ 11$ for $\{y\}$, but he receives a Vickrey payment of $€ 26-€ 25=€ 1$, since without his participation the total cost would be $€ 26$. In other words, the net payment of the buyer to supplier 1 is $€ 12$. Supplier 2 bids $€ 14$ for $\{x\}$, but receives a Vickrey payment of $€ 30-€ 25=€ 5$, because without his participation, the total cost of this auction would be $€ 30$. The advantage of VCG mechanisms is that they provide simple, dominant strategies for bidders. Unfortunately, they also exhibit a number of problems:

- The GVA requires bidders to submit bids on all $2^{m}-1$ possible bundles. Even if these bids will not enter the allocation, they can impact the Vickrey payments of bidders. Clearly, even with fairly small $m$, this can easily become impossible.

- The auctioneer needs to solve the allocation problem, which is NP-hard, but

\subsubsection{The Vickrey-Clarke-Groves mechanism}

also determine Vickrey payments for each winner, which is again an NPhard problem. All these problems need to be solved based on all possible bids of all bidders.

- In general, Vickrey auctions require a trusted auctioneer. An auctioneer could introduce synthetic bids to minimize Vickrey payments. Also, in a repeated setting, if the auctioneer is the buyer, he could use true information about the suppliers' costs in future auctions. Therefore, bidders will be reluctant in giving away their true cost. Cryptographic solutions to this problem have only been discussed for single-item Vickrey auctions (Brandt 2003).

In addition, all arguments are based on the assumption of having independent private costs. In case of affiliated valuations, iterative auctions, such as the English auction, have been advocated by theorists (Milgrom and Weber 1982).

\subsection{Open-cry auctions}

An open-cry auction enables bidders to learn about other bidders' cost (McAfee and McMillan 1987). These mechanisms are typically run in multiple rounds, which is why we will refer to them as iterative auctions. The U.S. FCC has almost exclusively considered iterative auctions for the design of spectrum licenses. They also seem to be attractive for industrial procurement applications (Hohner et al. 2003).

\subsubsection{General problems}

Cramton (1998) summarizes a number of general arguments for iterative auction designs, which hold also for the case of combinatorial auctions. In combinatorial auctions, bidders have the possibility to submit bids on bundles in later rounds which they did not consider in the first round as they learn about the competition. In the past few years, a number of iterative combinatorial auction formats have been developed (Brewer and Plott 1996; Parkes 1999; DeMartini et al. 2002; Wurman and Wellman 2000; Ausubel and Milgrom 2002). Researchers try to develop mechanisms with minimal complexity for bidders and the auctioneer without jeopardizing economic properties, such as allocative efficiency, strategy proofness, budget balance, or individual rationality. Some general problems of iterative com- 
binatorial auctions should be discussed below.

The threshold problem. describes the difficulty of small bidders to outbid a big bidder who is interested to sell many items. Let's assume a buyer wants to purchase three items $x, y$, and $z$. Bidders 1,2 , and 3 would each be willing to sell one of the items for $€ 3$. Bidder 4 wants $€ 10$ for all three items (private valuation). In round 1 , bidders 1, 2, and 3 have bid $€ 4$, while bidder 4 has already bid $€ 10$ for the bundle. None of the bidders 1, 2, and 3 can win by lowering his bid to his private cost, and bidders need to coordinate. This difficulty is one of the reasons why iterative auctions might end up with inefficient allocations.

The exposure problem. is typically discussed for simultaneous auctions, such as SMR. When two items should be purchased, a bidder wants both and not only one of the items, he risks winning only a single item in these parallel events. Bidders often shade their bids, which is one of the reasons for inefficiencies in these simultaneous auctions. Bundle bids mitigate this problem.

A similar problem can, however, also occur in combinatorial auctions. Let's assume, two items $x$ and $y$ should be bought. If a bidder bids on $x$ and $y$ and wants only one of the items, he might end up with the bundle $x y$ based on the winner determination formulation presented above. In particular, in iterative auctions, where bids are valid throughout the process, bidders want to make sure that they do not win multiple bids, although they only want one of them. An extension of this so called OR bidding language is the XOR bidding language, where only one of the bids of a bidder can become a winning bid. In this case, the auctioneer adds side constraint (c) to the WDP:

$\sum_{j \in L^{i}} x_{i j} \leqslant 1 \quad \forall i \in N$

As a consequence, bidders need to specify a larger number of bids for all combinations of items they are interested in. Logic bidding languages of this sort should allow bidders to describe their preferences easily. OR and XOR bidding languages are two examples. Also combinations and extensions have been discussed (Nisan 2000; Fujishima et al. 1999).

Tie breaking:. In traditional auctions auctioneers typically choose the first of two equal bids. In combinatorial auctions, an allocation comprises multiple bids and an auction round might contain multiple allocations with the same total cost. The auctioneer needs to decide whether he wants to choose the allocation that was possible first, or the allocation with the lowest average time stamp, or other rules and it obviously takes more effort to break ties (Hohner et al. 2003).

Ask prices:. In iterative auction formats, ask prices help bidders to determine, how much less to bid in order to become a winner in the next round. In single-item auctions, a bidder needs to bid less than the current standing bidder. In combinatorial auctions, this is not obvious. If the current allocation of three items A, B, and C is that the bundle of item $A$ and $B$ go to supplier 1 and item $\mathrm{C}$ goes to supplier 2, the loosing bidder 3, who is interested in the bundle of item $B$ and $C$, does not know how much less to bid in the next round. This depends on the set of loosing bids in the auction.

Bikhchandani and Ostroy (2001) show in their fundamental contribution that in the presence of bundle bids the only types of ask prices that are always possible are non-linear and personalized. In other words, there might be a price for every bundle and this bundle price might be different from bidder to bidder. The authors draw on linear programming duality theory in their work. This insight is fundamental. The second theorem of welfare economics states that any efficient allocation can be sustainable by a Walrasian equilibrium, i. e., item-level or linear prices (Mas-Colell et al. 1995). In combinatorial auctions, some of the assumptions in welfare economics are violated, and one cannot always find linear ask prices. Obviously, the sheer volume of non-linear and personalized ask prices is a disadvantage. Nevertheless, some researchers have proposed practical auction designs based on this type of prices. Others have decided to approximate linear ask prices. The type of ask prices is the main difference among practical combinatorial auction designs.

\subsubsection{Selected combinatorial auction designs}

A number of designs for iterative combinatorial auctions have been proposed recently. The discussion on the design of the U.S. FCC spectrum auctions was certainly one of the drivers for this increased interest. The Adaptive User Selection
Mechanism (AUSM) was one of the first proposals (Banks et al. 1989). Here, the allocation problem is delegated to bidders and a public white board should help them to coordinate their bundle bids and suggest new composite bids that have a lower total cost for the buyer. Most newer auction designs have the auctioneer calculate the optimal allocation (Weinhardt et al. 1999; DeMartini et al. 2002; Porter et al. 2003; Parkes 1999; Wurman and Wellman 2000; Ausubel and Milgrom 2002; de Vries et al. 2003). In the following, we will provide a brief overview of the main proponents:

The Resource Allocation Design (RAD) approximates linear ask prices and combines them with a number of activity rules from SMR. RAD requires monotonicity in the number of items a bidder demands. This means, in each round a bidder can only bid on as many items in his bids as he bid on in the previous rounds. The ask price for a bundle is simply the sum of the item prices in this bundle. Bidders need to bid below the ask prices minus the bid decrement (in reverse auctions). The LPbased heuristic to calculate ask prices is specific to RAD (DeMartini et al. 2002).

An alternative and simple approach has been proposed by Porter et al. (2003). The combinatorial clock auction (CC) proceeds like a Japanese auction on multiple items. For each item, there is an item clock showing the current ask price per item. In each round the bidder determines which bundles he wants to bid on at the current prices. Ask prices for bundles are again linear. The clock starts at a very high price and is decreased round by round as long as there is competition on this item, i. e., as long as there is more than one bidder interested in selling the item. After a certain number of auction rounds, there should be linear ask prices determining the allocation. There might be cases in which the ask prices are too low to have any bidder any more. In these cases, the auctioneer solves the WDP based on all bids submitted in the auction. In experimental analyses the CC auction led to higher efficiency compared to SMR in cases with cost complementarities. As in $\mathrm{RAD}$, the linear ask prices used in the CC auction can lead to inefficiencies.

A number of scientists have tried to address the inefficiencies due to linear prices by using non-linear ask prices (Parkes 1999; Wurman and Wellman 2000; Ausubel and Milgrom 2002; de Vries et al. 2003). These auctions are sometimes referred to as primal-dual auctions, as the way how the 


\section{Abstract \\ Martin Bichler, Alexander Pikovsky, Thomas Setzer \\ An Analysis of Design Problems in Combinatorial Procurement Auctions}

Traditional auction mechanisms support price negotiations on a single item. The Internet allows for the exchange of much more complex offers in real-time. This is one of the reasons for much research on multidimensional auction mechanisms allowing negotiations on multiple items, multiple units, or multiple attributes of an item, as they can be regularly found in procurement. Combinatorial auctions, for example, enable suppliers to submit bids on bundles of items. A number of laboratory experiments has shown high allocative efficiency in markets with economies of scope. For suppliers it is easier to express cost savings due to bundling (e.g., decreased transportation or production costs). This can lead to significant savings in total cost of the procurement manager. Procurement negotiations exhibit a number of particularities:

- It is often necessary to consider qualitative attributes or volume discounts in bundle bids. These complex bid types have not been sufficiently analyzed.

- The winner determination problem requires the consideration of a number of additional business constraints, such as limits on the spend on a particular supplier or the number of suppliers.

- Iterative combinatorial auctions have a number of advantages in practical applications, but they also lead to new problems in the determination of ask prices.

In this paper, we will discuss fundamental problems in the design of combinatorial auctions and the particularities of procurement applications.

Reprint ofanarticle fromWIRTSCHAFTSINFORMATIK 47(2)2005:126-134.

Keywords: Combinatorial auction, Multidimensional auction, Industrial procurement, Combinatorial optimization efficient solution is found can be modeled similar to primal-dual or subgradient algorithms in linear programming (Nemhauser and Wolsey 1988). Here, the dual variables are interpreted as ask prices in an auction. iBundle is one of these auction designs (Parkes and Ungar 2000). Prices for each loosing bundle and bidder are decreased by a minimum bid increment from round to round. Assuming straightforward bidding, this means that every bidder submits bids on those bundles that maximize his payoff, this auction format leads to efficient allocations. Ausubel and Milgrom have suggested the use of proxy agents, in order to deal with the many auction rounds that this format causes (Ausubel et al. 2003).

\section{Applications in industrial procurement}

Companies such as CombineNet (http:// www.combinenet.com), NetExchange (http://www.netex.com) and Trade Extensions (http://www.tradeextensions. com) provide software for combinatorial auctions. Although there are a number of press announcements about the use of combinatorial auctions for transportation and industrial procurement, there are only a few published cases. We have analyzed the literature and conducted a number of phone interviews with representatives of these three companies. Based on this initial survey, combinatorial auctions have been used for the procurement of very different types of items (office supply, chemicals, transportation services, package material, etc.). In most cases there are larger quantities of items with a high degree of cost complementarities for suppliers. Vendors reported auctions with 10 items, but also cases with many thousands items. Similarly, the number of bidders varied. There were cases with several hundred bidders; 10 to 20 bidders were seen as average numbers for industrial procurement applications, however. Even though the number of empirical observations is limited, the results of these interviews illustrate the versatility of combinatorial auctions as a means for online negotiations in industrial procurement.

Procurement applications have been conducted both as sealed-bid and as iterative auctions. Iterative auctions were typically run without ask prices, providing bidders only information about the winning allocation. We did not learn about any use of VCG mechanisms in this domain. What has been described as essential to procurement applications by all respondents was the consideration of additional side constraints such as upper and lower bounds on the number of winners or spend on a supplier. Also, some vendors used extensions of pure bundle bids including qualitative attributes and quantity of an item.

- Cost savings were seen as the main motivation for the use of combinatorial auctions in procurement organizations. According to the vendors, combinatorial auctions delivered on their promise and they quoted cost savings of up to $13 \%$ on average. This can mostly be attributed to higher allocative efficiency of these auctions.

- Decreased transaction costs for complex procurement negotiations: Combinatorial auctions allow for effective negotiations on multiple items. The alternative to combinatorial bidding are either sequential or simultaneous auctions or bilateral negotiations on the phone, which is time-consuming and expensive (see also Hohner et al. 2003).

- Transparency and fairness: Open and iterative auctions increase the market transparency, which was seen as a positive feature by suppliers. Also, all suppliers are treated equally, which led to a high perceived fairness by the suppliers.

- Allocative efficiency: In particular in cases with significant cost complementarities for suppliers, combinatorial auctions led to high allocative efficiency compared to other types of auctions (Porter et al. 2003).

\section{Summary}

The U.S. FCC spectrum auctions have spawned intensive discussion on the design of combinatorial auctions. Overall, however, industrial procurement might be one of the most interesting application domains. Cost savings for the purchasing manager, decreased transaction costs, transparency, and fairness are among the main advantages. However, the application of combinatorial auctions leads to a number of fundamental design problems such as the computational complexity of the winner determination problem or the strategic complexity for bidders. In addition, procurement applications have specific requirements such as the con- 
sideration of additional side constraints and the need for other, multidimensional bid types. A number of promising auction designs has been proposed, but to date, a solid theoretical and empirical evaluation of these designs is missing. In the long run, this research area might lead to robust and efficient auction designs and standard software solutions for multi-item negotiations in procurement.

\section{References}

Ausubel L, Cramton P, Milgrom P (2003) A practical combinatorial auction: the clock-proxy auction. Working paper, Stanford University

Ausubel L, Milgrom P (2002) Ascending auctions with package bidding. Working paper, University of Maryland

Banks J, Ledyard JO, Porter D (1989) Allocating uncertain and unresponsive resources: An experimental approach. RAND Journal of Economics 20:1-25

Beall S, Carter C, Carter PL et al (2003) The role of reverse auctions in strategic sourcing. Center for Advanced Purchasing Studies (CAPS)

Bichler M (2000) An experimental analysis of multi-attribute auctions. Decision Support Systems 28(3)

Bichler M (2001) The future of e-markets: multidimensional market mechanisms. Cambridge University Press, Cambridge

Bichler M, Kalagnanam J (2005) Configurable offers and winner determination in multi-attribute auctions. European Journal of Operational Research

Bichler M, Kalagnanam J, Kaircioglu K et al (2002) Applications of flexible pricing in business-tobusiness electronic commerce. IBM Systems Journal 41(2)

Bichler M, Klimesch R (2000) Simulation multivariater Auktionen - eine Analyse des Handels mit Finanzderivaten. WIRTSCHAFTSINFORMATIK 42(3)

Bichler M, Kaukal M, Segev A (1999) Multi-attribute auctions for electronic procurement. In: First IBM IAC workshop on internet based negotiation technologies, Yorktown Heights

Bikhchandani S, Ostroy J (2001) The package assignment model. UCLA

Branco F (1997) The design of multidimensional auctions. RAND Journal of Economics 28(1):6381

Brandt $F$ (2003) Fully private auctions in a constant number of rounds. In: Wright RN (ed) Financial Cryptography. Springer, Heidelberg, pp 223-238

Brewer PJ, Plott CR (1996) A binary conflict ascending price (bicap) mechanism for the decentralized allocation of the right to use railroad tracks. International Journal of Industrial Organization 14(6):857-886

Che YK (1993) Design competition through multidimensional auctions. RAND Journal of Economics 24(4)
Cramton P (1998) Ascending auctions. European Economic Review 42(3-5):745-756

Cramton P, Shoham Y, Steinberg R (eds) (2005) Combinatorial auctions. MIT Press

Davenport A, Kalagnanam J (2000) Price negotiations for procurement of direct inputs. Workshop report, IMA hot topics workshop: mathematics of the internet: e-auction and markets

DeMartini C, Kwasinak T, Ledyard JO et al (2002) A new and improved design for multi-object iterative auctions. Social Science Working Paper 1054, California Institute of Technology

Elmaghraby W, Keskinocak P (2002) Combinatorial auctions in procurement. Georgia Tech

Epstein R, Henriquez L, Catalan J et al (2002) A combinatorial auction improves school meals in Chile. Interfaces 32(6)

Ewerhart C, Moldovanu B (2003) The German UMTS design: insights from multi-object auction theory. In: Illing $\mathrm{G}$ (ed) Spectrum auction and competition in telecommunications. MIT Press

Fujishima Y, Leyton-Brown K, Shoham Y (1999) Taming the computational complexity of combinatorial auctions: Optimal and approximate approaches. In: International joint conference on artificial intelligence (IJCAI), Stockholm

Groves T (1973) Incentives in teams. Econometrica 41:617-631

Hannon D (2004) GSK closes the loop using esourcing tools. Purchasing Magazine. http:// www.purchasing.com/article/CA422096.html. Accessed 2004-07-28

Hohner G, Rich J, Reid G et al (2003) Combinatorial and quantity-discount procurement auctions benefit mars incorporated and its suppliers. Interfaces

Isaac MR, James D (2000) Robustness of the incentive compatible combinatorial auction. Experimental Economics 3(1)

Jackson MO (2000) Mechanism theory. In: The Encyclopedia of Life Support Systems, EOLSS Publishers

Kagel J (1995) Auctions - a survey of experimental research. In: Kagel J, Roth Al (eds) The Handbook of Experimental Economics. Princeton University Press, pp 501-585

Klemperer P (1999) Auction theory: a guide to the literature. J Economic Surveys 13(3):227286

Koboldt C, Maldoom D, Marsden R (2003) The first combinatorial spectrum auction. Discussion Paper 03/01, econ

Krishna V, Rosenthal R (1996) Simultanous auctions with synergies. Games and Economic Behavior 17:1-31

Kwasniak T, Ledyard JO, Porter D et al (2003) A new and improved design for multi-objective iterative auctions. Management Science

Ledyard JO, Olson M, Porter D et al (2001) The first use of a combined value auction for transportation services. Interfaces

Mas-Colell A, Whinston MD, Green JR (1995) Microeconomic Theory. Oxford University Press, Oxford

McAfee R, McMillan PJ (1987) Auctions and bidding. J Economic Literature 25:699-738

McMillan J (1994) Selling spectrum rights. J Eco- nomic Perspectives 8(3):145-162

Milgrom P (2000) Putting auction theory to work: the simultaneous ascending auction. J Political Economy 108(21):245-272

Milgrom PR, Weber RJ (1982) A theory of auctions and competitive bidding. Econometrica 50:1089-1122

Myerson RB, Satterthwaite MA (1983) Efficient mechanisms for bilateral trade. J Economic Theory 29:265-281

Nemhauser G, Wolsey L (1988) Integer and Combinatorial Optimization. Wiley, Chichester

Nisan N (2000) Bidding and allocations in combinatorial auctions. In: ACM conference on electronic commerce (EC-2000), Minneapolis

Parkes DC (1999) ibundle: an efficient ascending price bundle auction. In: ACM conference on electronic commerce, Denver, pp 148-157

Parkes DC, Ungar LH (2000) Preventing strategic manipulation in iterative auctions: proxyagents and price-adjustment. In: 17th national conference on artificial intelligence (AAAI-00)

Porter D, Rassenti S, Roopnarine A et al (2003) Combinatorial auction design. Proceedings of the National Academy of Sciences of the United States of America (PNAS)

Rassenti SJ, Smith V, Bulfin RL (1982) A combinatorial auction mechanism for airport time slot allocation. Bell Journal of Economics 13:402417

Robinson MS (1985) Collusion and the choice of auction. RAND Journal of Economics 16:141145

Rothkopf MH, Pekec A (1998) Computationally manageable combinatorial auctions. Maryland auction conference, Maryland

Sandholm T (1999) Approaches to winner determination in combinatorial auctions. Decision Support Systems 28(1):165-176

Strecker S (2003) Preference revelation in multiattribute reverse english auctions: a laboratory study. In: International conference on information systems (ICIS), Seattle

Vickrey W (1961) Counterspeculation, auctions and competitive sealed tenders. J Finance 16(1):8-37

de Vries S, Vohra R (2003) Combinatorial auctions: a survey. INFORMS Journal of Computing 15(3):284-309

de Vries S, Schummer J, Vohra R (2003) On ascending vickrey auctions for heterogeneous objects. In: FCC combinatorial bidding conference 2003

Weinhardt C, Gomber P, Schmidt C (1999) Pricing in multi-agent systems for transportation planning. J Organizational Computing and Electronic Commerce

Weinhardt C, Holtmann C, Neumann D (2003) Market engineering. WIRTSCHAFTSINFORMATIK 45(6)

Wolfstetter E (1996) Auctions: an introduction. J Economic Surveys 10(4):367-420

Wurman P, Wellman MP (2000) Akba: a progressive, anonymous-price combinatorial auction. In: ACM conference on electronic commerce, Minneapolis, pp 21-29 